Statins (inhibitors of 3-hydroxy-3-methyl-glutaryl-coenzyme $A$ reductase) are a group of drugs used to treat lipid disorders. They inhibit cholesterol synthesis at an early stage of the biosynthesis pathway, thus eliminating numerous metabolites involved in the cycle. Numerous studies point to different possible effects of statins on cancer cells. Statins inhibit growth of a tumor, invasion and metastasis formation. They block the production of isoprenoids, which are necessary for post-translational modifications of many proteins, including those involved in normal cell signaling. They also contribute to the reduction in the expression of vascular endothelial growth factor, sensitize tumor cells to NK cell activity, and modify the body inflammatory response. Due to different pharmacokinetic properties of individual statins, they may have opposite effects on the risk of cancer. Currently, most information on the effects of statins on the risk of developing cancer is obtained from observational studies. The studies have different results depending on the location of cancer. The protective effect of statins was observed in the meta-analysis of numerous studies including prostate cancer, stomach cancer, esophagus cancer, and hepatocellular carcinoma; however, it has not yet been confirmed that statins influence the risk of developing colorectal cancer, breast cancer, or lung cancer. The protective effect of statins on the development of many kinds of cancer can be a valuable and easy way to reduce morbidity. However, further research is necessary to thoroughly determine the value of this group of drugs.

Key words: statins, cancer, prostate cancer, gastrointestinal cancers.

Contemp Oncol (Pozn) 2015; 19 (3): 167-175 DOI: $10.5114 /$ wo.2014.44294

\section{Statins and cancers}

\author{
Aleksandra Stryjkowska-Góra ${ }^{1}$, Bożenna Karczmarek-Borowska ${ }^{1,2}$, \\ Tomasz Góra ${ }^{3}$, Katarzyna Krawczak ${ }^{1}$
}

${ }^{1}$ Department of Clinical Oncology, Podkarpacie Oncology Center, Rzeszow, Poland ${ }^{2}$ Department of Oncology, Faculty of Medicine, University of Rzeszow, Poland ${ }^{3}$ Department of Gynaecology and Obsterics, F. Chopin Provincial Hospital, Rzeszow, Poland

\section{Introduction}

Inhibitors of 3-hydroxy-3-methyl-glutaryl-coenzyme A reductase (HMGCoA), known as statins, are a commonly used and well-tolerated class of drugs for the treatment of lipid disorders, in particular hypercholesterolemia. Their effectiveness in preventing the development of cardiovascular diseases means that statins are among the most widely used drugs [1, 2].

Current results also indicate their protective effect on the development of various types of cancer - the authors also reported a variety of target points at the molecular level. The protective effect of statins reported in many current papers offers a potentially valuable contribution to modern medicine.

This paper is intended to outline the current state of knowledge concerning the potential mechanisms of action of statins on cases of malignant cancer, as well as to present conclusions of clinical research that encourage further exploration. Due to a huge amount of observational studies, the results presented in this paper will be restricted to the presentation of the results of the latest cohort studies and meta-analysis concerning the relation between statin use and prostate cancer, colorectal cancer, lung cancer and breast cancer development.

\section{The mechanism of action of statins and cancer}

Statins inhibit HMG-CoA conversion to a precursor of sterols, mevalonate. Since mevalonate production takes place at an early stage of the cholesterol synthesis pathway, statins also inhibit the synthesis of a number of other metabolites. In this mechanism the production of isoprenoids, which serve as a substrate for post-translational modifications of many proteins, including farnesyl pyrophosphate and geranylgeranyl pyrophosphate, is blocked (Fig. 1) [3].

Many products of the mevalonate synthesis pathway are also essential for other critical cellular functions such as cell membrane integrity and protein synthesis, and the interference in these processes initiated by statins may influence the growth and development of cancer cells [4].

The isoprenoids are responsible for prenylation of Ras and Rho proteins and are necessary for their translocation to the plasma membrane, which is required for intracellular signaling [5]. The GTPases play an important role in cellular processes such as apoptosis, phagocytosis, vascular trafficking, cellular proliferation and transmigration, cytoskeleton dynamics, and recruitment of inflammatory cells. This inactivation of the small GTPases (Rho, Racs, Rac and (dc24) may be responsible for the observed effects of statins and their effect on the proliferation, mortality and invasiveness of cancer cells (Fig. 1) [3].

The inhibition of an invasion is mediated by inactivation of RhoA, a protein belonging to the family of Rho proteins that regulates changes of actin cytoskeleton during cell movement and activates cell contraction. Statin-induced apoptosis is mainly caused by inhibition of geranylgeranylated 


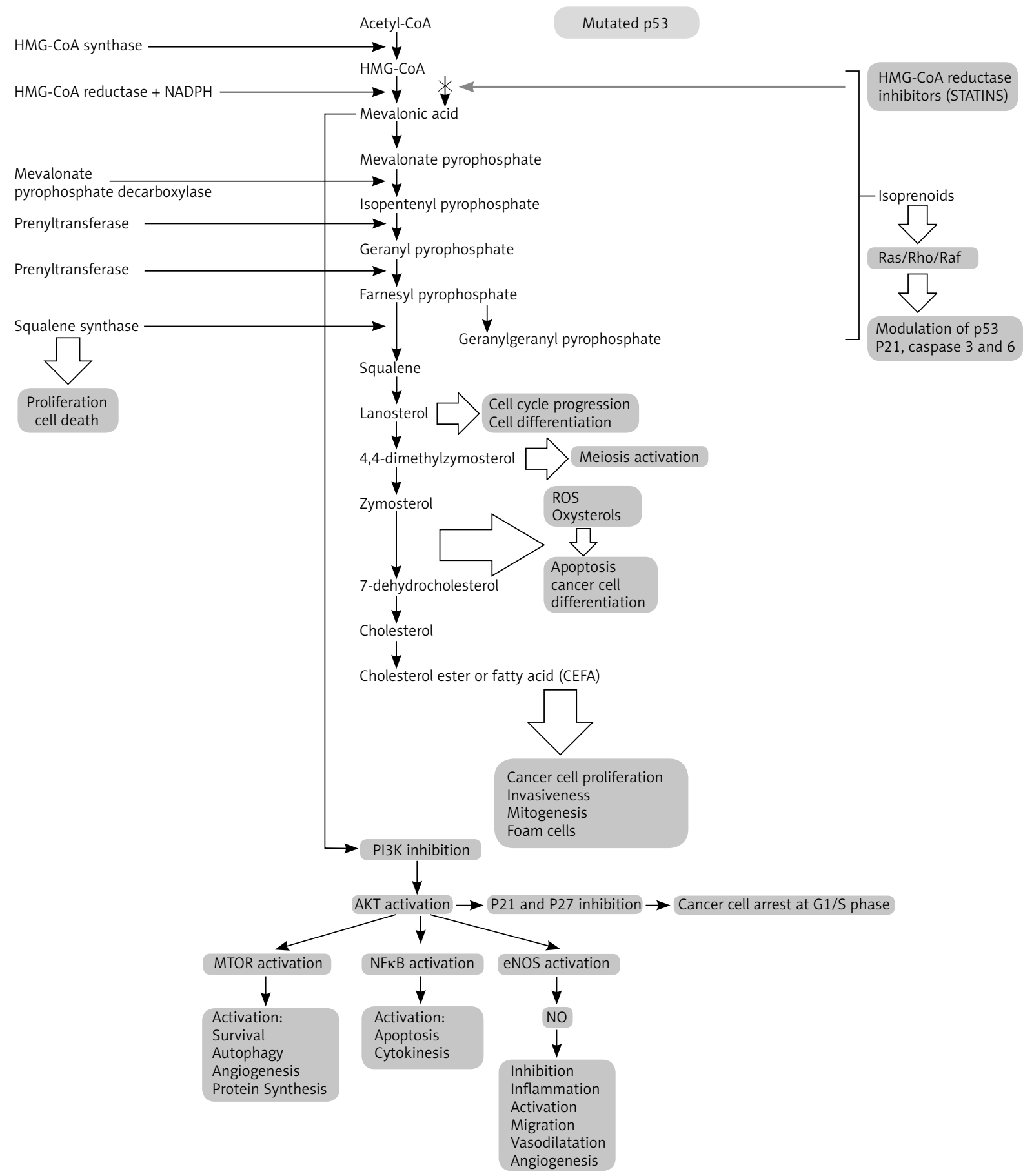

Fig. 1. Mechanism of action of statins and cancer

proteins [3], but it is also currently suggested that the proapoptotic effect results from activation of proteins of the Bcl-2 family [6].

Inhibition of ROS (reactive oxygen species) production by the suppression of Rec1/NADPH oxidase activity and by influencing the activity of GPx (glutathione peroxidase) and catalase helps to reduce the expression of vascular endothelial growth factor (VEGF), and consequently can inhibit angiogenesis, for example in non-small cell lung cancer [7].
Tests on two human melanoma cell lines revealed that statins increase the expression of protein A related to MHC class I chain (MICA), which makes these cells more sensitive to NK cells [8]

Recently attention was drawn to the possible potential suppressive effect of statins on tumor growth by inhibiting matrix metalloproteinases (matrixins - MMPS). MMPs can degrade extracellular matrix components involved in such processes as growth of a tumor, invasion or metastasis formation [4]. There is increasing evidence that MMPs 
have both protumorigenic as well as antitumorigenic functions, depending on the stage of the disease, the patient's genotype and, above all, the type of MMPs [9]. In particular, MMP-2 and MMP-9, expressed by cells of various malignant tumors, are closely related to invasive and metastatic properties of the cells, and also play a critical role in the degradation of type IV collagen [10]. Recent studies have shown that several members of this family, including MMP8, MMP12, and MMP26, provide a protective effect in different stages of cancer progression. For instance, MMP8 is a protease that is mainly produced by neutrophils and is associated with inflammatory conditions. The results of several studies indicate that MMP8 is an important tumor-protective factor with the ability to influence both the primary tumor growth and the metastatic potential of malignant cells [11]. Among implied mechanisms of action, it is mentioned, inter alia, that statins may reduce the MMP-2 and MMP-9 gene transcription and inhibit peripheral blood mononuclear cell proliferation by lowering the release of inactive MMP proforms [9].

Statins have pleiotropic effects on cell survival, cell adhesion, migration, proliferation [12], immunoregulation, antioxidant activity, endothelial function, and angiogenesis, and they can also reduce the activation of the blood coagulating cascade [13].

Statins also have indirect anti-inflammatory properties by affecting C-reactive protein (CRP) [14], IL-6, IL-8 [15], IL-1 $\beta$, IL-12, tumor necrosis factor $\alpha$ (TNF- $\alpha)$ [16], and nuclear factor $\kappa \mathrm{B}(\mathrm{NF}-\kappa \mathrm{B})[3]$.

The antiproliferative effect is obtained, among other methods, by blocking the transition from G1 to $S$ in the cell cycle [17]. The radiation sensitizing effect is most likely caused by the retention of cells in the late G1 phase of a cell cycle [18].

In a multiple cell model, statins were found to significantly increase the level of regulatory $T$ cells in vivo and in vitro by inducing transcription factor Foxp3. The immunomodulatory effect of statins may reduce the host's anticancer response by modulating the activity of $T$ lymphocytes [19].

Some authors question the assumption that the main anticancer effect of statins is their inhibitory effect on the production of isoprenoid in cancer cells. They assume that statin treatment inhibits HMG-CoA reductase mainly in the liver, but not in the cells of solid tumors situated outside the liver. Anti-tumor activity in peripheral tissues is believed to be developed indirectly and results from a systemic decrease in low-density lipoprotein (LDL) [20]. It is a fact that statins are selectively taken up by the liver and not more than $5 \%$ of the administered dose reaches the circulatory system. This selective hepatic uptake and low peripheral availability casts doubt on the potential protective effect of statins. Observations confirm that men with low levels of serum cholesterol have a lower risk of developing advanced prostate cancer [21]. Many studies performed in vitro indicate a direct effect of statins on the cell cycle, intra- and intercell signaling processes and cell apoptosis. This fact may suggest that the anticancer effect of statins is a much more complex phenomenon and not only a result of their cholesterol-lowering effect [3]. As in studies on multiple cell lines, the statins were adminis- tered in concentrations higher than in clinical practice so it is difficult to assess the actual impact on the process of carcinogenesis in the human body.

The levels of serum esterase in human blood are low, so the prodrug statins accumulate easily in extrahepatic tissues, increasing its peripheral bioavailability. In spite of the fact that statin therapy inhibits 3-hydroxy-3-methylglutaryl-CoA reductase primarily in the liver, it is also possible that in selected anatomic sites the pleiotropic effects of statins may modulate "cholesterol-sensitive" pathways of cancer cells [9]. The final word on whether the antitumor effect of statins results from a reduction in serum cholesterol or has a direct effect on tumor cells requires further studies.

Currently on the market there are seven classes of medicines: lovastatin, simvastatin, fluvastatin, pravastatin, atorvastatin, rosuvastatin and pitavastatin (the last one still not registered in Poland). The differences in the pharmacokinetic properties of hydrophilic statins (e.g., pravastatin) compared to hydrophobic ones (e.g. lovastatin, simvastatin) may affect the risk of developing cancer in the opposite way [4]. The differences in the hydrophilic properties of statins may explain the increase in the risk of developing cancer among patients taking pravastatin in two large randomized controlled trials (RCTs) [4]. Fluvastatin presents indirect pharmacokinetic properties. Several RCTs dealing with the use of statins and coronary heart disease have reported incidental cases of developing cancer, but most of these results were ambiguous due to their low statistical power. In one study, however, pravastatin was associated with an increased risk of developing breast cancer, and, in another one, generally with an increased risk of cancer concerning especially cancers originating from the gastrointestinal tract. However, there was not any other large and credible randomized controlled trial proving an increased risk of developing cancer [4].

\section{Clinical research}

Most information on the potential impact of statins on cancer was obtained from observational studies, which due to their scope are essential for pharmacoepidemiology but do not take into account numerous factors that could distort the results. One should bear in mind the fact that people taking statins at the same time are often treated with medication due to diseases of the cardiovascular system (e.g. acetylsalicylic acid). They are usually elderly, with a higher BMI, incorrect feeding, a sedentary lifestyle, and also people in this group are relatively more frequently dependent on tobacco. The above-mentioned factors also influence the chance of developing cancer to a different degree. The majority of research focuses on assessing the risk of developing cancer among patients taking statins.

A recently published paper concludes that statins improve survival among patients with cancer. Nielsen et al. [22] investigated the relationship between taking statins before the diagnosis of cancer and its related mortality. A nationwide Danish population-based cohort study was conducted among adults (> 40 years of age) between 1995 and 2009. 18,721 had used statins regularly before a cancer diagnosis, and 277,204 had never used statins. Compared 
with the patients who had never received statins before the diagnosis of cancer, those who had been taking statins before the diagnosis had a 15\% lower risk of dying from any cause (adjusted HR: $0.85,95 \% \mathrm{Cl}: 0.83-0.87$ ) as well as from cancer specifically (adjusted HR: 0.85, 95\% Cl: 0.82-0.87). Improved survival with statin exposure was seen in patients with 13 types of cancer, including the 4 most common cancers - lung cancer (HR: 0.87, 95\% Cl: 0.83-0.92), colorectal cancer (adjusted HR: 0.87, 95\% Cl: 0.75-0.85), prostate cancer (adjusted HR: 0.81, 95\% Cl: 0.75-0.88) and breast cancer (adjusted HR: 0.88, 95\% Cl: 0.80-0.99).

On the basis of the newest papers concerning the association between statins use and cancer, the authors will try to present the impact of statins on the risk of developing different forms of neoplasms, survival and recurrence rate. Nowadays, most available publications are focused on the risk of morbidity, which is why such results will dominate this paper.

\section{Statins and prostate cancer}

Currently a huge number of clinical studies evaluating the effect of statins on the development of a variety of solid tumors are being conducted worldwide. A lot of attention is also being given to prostate cancer. Prostate cancer is the second most common cancer in men in Poland.

The prostate gland synthesizes large amounts of cholesterol, most likely due to androgens, for which the prostate is the target organ. Androgens stimulate lipogenesis in prostate cells by increasing transcription of genes such as those encoding FAS (fatty acid synthase), and HMG-CoA reductase [23]. In another study, over 300 androgen-dependent transcripts were identified, which mainly encode proteins involved in lipid metabolism [24].

While looking for evidence of the association between statins and a reduced risk of prostate cancer, D. Bansal et al. conducted a meta-analysis which included 27 (15 cohort and 12 case-control) studies. Statin therapy significantly reduced the risk of total prostate cancer incidence (risk of total PCa) by $7 \%$ (RR 0.93, 95\% Cl: 0.87-0.99, $p=0.03$ ) and clinically important advanced prostate cancer by $20 \%$ (RR 0.80, 95\% Cl: 0.70-0.90, $p<0.001$ ). Long-term use of statins had no significant effect on the risk of morbidity (RR 0.94, 95\% Cl: 0.84-1.05, $p=0.31$ ). The aforementioned meta-analysis provided evidence supporting the hypothesis that statins reduced the risk of prostate cancer [25].

Murtola et al. [26] presented data on the effects of individual drugs from the group of statins. While analyzing a large group (24 723 cases), the authors observed a significant reduction in the risk of developing advanced prostate cancer among patients taking atorvastatin, lovastatin and simvastatin. The researchers found that other cholesterol-lowering drugs (mostly fibrates) appeared to reduce the risk of advanced prostate cancer, but these results are not statistically significant due to the limited length of their clinical trial.

Tan et al. [27] analyzed data from 4204 patients (3182 not on statins and 1022 on statins). Statin use was associated with a decreased risk of prostate cancer, less frequent high-grade prostate cancer, and, in general, a lower volume of prostate cancer.
Yu O et al. [28] analyzed a cohort of 11,772 men on whether the use of statins after prostate cancer diagnosis was associated with a decreased risk of cancer-related mortality and all-cause mortality. The results indicated that postdiagnostic use of statins was associated with a decreased risk of prostate cancer mortality ( $\mathrm{HR}, 0.76 ; 95 \% \mathrm{Cl}$ : 0.66-0.88) and all-cause mortality (HR, 0.86; $95 \% \mathrm{Cl}$ : 0.78-0.95). However, this effect was stronger in patients who also used statins before diagnosis.

According to Soto DE research [29], statin use did not affect progression-free survival (PFS) after radiotherapy for prostate cancer. It is worth noting that T stage, baseline prostate-specific antigen level, and Gleason score were critical determinants of prostate-specific antigen failure. These results did not differ when hydrophilic pravastatin was excluded.

Allott et al. [30] investigated the effect of postoperative statin use on biochemical recurrence (BCR) in prostate cancer patients treated with radical prostatectomy (RP) who never used statins before surgery. In this retrospective cohort study of 1,146 RP patients, postoperative statin use was significantly associated with $36 \%$ reduced risk of BCR (HR $0.64 ; 95 \% \mathrm{Cl}: 0.47-0.87 ; p=0.004)$. The fact is that only randomized controlled trials are warranted to formally test the hypothesis that statins slowed prostate cancer progression; therefore we have to wait for the final results.

On the other hand, according to the research of Chao et al. [31], statin use may not prevent prostate cancer progression following radical prostatectomy (Table I). Results of the meta-analysis by Scosyrev et al. [32] did not show significant differences between treatment groups (Table 1).

\section{Statins and gastrointestinal cancers}

Singh et al. conducted a meta-analysis of 11 studies (8 observational, 3 post-hoc analyses of 26 clinical trials) which included 5581 cases of gastric cancer. Their study showed a significant $32 \%$ reduction in the risk of gastric cancer among patients taking statins (adjusted OR, 0.68, $95 \% \mathrm{Cl}: 0.51-0.91)$. The study indicated a protective effect of statins on the risk of gastric cancer in both Asian and Western populations [33]. The researchers also conducted a meta-analysis of the studies investigating the effect of statins on the risk of developing esophagus cancer, with particular focus on patients diagnosed with Barrett's esophagus and hepatocellular carcinoma. A significant reduction in the risk of developing these kinds of cancer among patients taking statins was observed in both studies. In the case of esophagus cancer the reduction of risk reached 28\% (adjusted OR, 0.72, 95\% Cl: 0.60-0.86) (conclusions from 13 studies), and in the case of hepatocellular carcinoma a reduction in the risk of developing it was also observed (adjusted OR, 0.63, 95\% Cl: 0.52-0.76) wherein the results concern a heterogeneous group. A clearer correlation was observed in the Asian population [34, 35].

Colon and rectal cancers are among the most common malignant cancers in Poland and abroad. It is not surprising that many researchers have started analyzing the impact of commonly used statins on the development of these cancers. 
Table 1. The latest research on the relationship between statin use and prostate cancer

\begin{tabular}{|c|c|c|}
\hline Author, year & Number of cases & Results [point estimate $(95 \% \mathrm{Cl})]^{\star *}$ \\
\hline $\begin{array}{l}\text { Tan et al. } 2011 \\
{[27]}\end{array}$ & 4204 & $\begin{array}{l}\text { Adjusted risk ratio for prostate cancer diagnosis: } 0.92 \text { (Cl: } 0.85-0.98) \\
\text { Adjusted risk ratio for high-grade prostate cancer ( }(\mathrm{Gleason} \geq 7): 0.76 \text { (Cl: } 0.67-0.85) \\
\text { Adjusted risk ratio for } 3 \text { or more cores positive: } 0.86 \text { (Cl: } 0.75-0.97)\end{array}$ \\
\hline $\begin{array}{l}\text { Yu et al. } 2014 \\
{[28]}\end{array}$ & 11772 & $\begin{array}{l}\text { Prostate cancer mortality } \\
\text { HR, 0.76; } 95 \% \mathrm{Cl}: 0.66-0.88 \\
\text { All-cause mortality } \\
\text { HR, } 0.86 ; 95 \% \text { Cl: } 0.78-0.95\end{array}$ \\
\hline $\begin{array}{l}\text { Chao et al. } 2013 \\
\text { [31] }\end{array}$ & 1200 & $\begin{array}{l}\text { Biochemical recurrence: } \\
\mathrm{HR}=1.00(0.72-1.39)-\text { preoperative statin use } \\
\mathrm{HR}=1.05(0.76-1.46)-\text { postoperative statin use } \\
\text { Clinical disease progression } \\
\mathrm{HR}=0.63(0.31-1.27)-\text { preoperative statin use } \\
\mathrm{HR}=1.20(0.63-2.30)-\text { postoperative statin use }\end{array}$ \\
\hline Scosyrew et al. 2013 [32] & & $\begin{array}{l}\text { Biochemical recurrence (statin users vs. non-users) } \\
\text { For entire set of eight studies: } \\
\mathrm{HR}=0.91(0.72-1.13) \\
\text { For radical prostatectomy: } \\
\mathrm{HR}=1.02(0.80-1.29) \\
\text { For radiotherapy: } \\
\mathrm{HR}=0.71(0.44-1.16)\end{array}$ \\
\hline Allott et al. 2014 [30] & 1146 & $\begin{array}{l}\text { Reduced risk of biochemical recurrence } \\
\mathrm{HR} 0.64 ; 95 \% \mathrm{Cl}: 0.47-0.87 ; p=0.004\end{array}$ \\
\hline
\end{tabular}

** $O R$-odds ratio; $R R$ - relative risk; $H R$ - hazard ratio; $\mathrm{Cl}$-confidence interval; relative to non-users of statin

Duijnhoven et al. [36] analyzed the test results of participants of the European project concerning links between diet and the risk of malignant cancer (European Prospective Investigation into Cancer and Nutrition, EPIC). Observation of the data concerning 520,000 people, including 1,238 patients with colon and rectal cancer, showed a link between high levels of high-density lipoprotein $(\mathrm{HDL})$ and a decrease in the risk of developing colon cancer. The mechanism conditioning this relationship is uncertain, but the result suggests a link between the incidence of colon cancer and lipid abnormalities. The review of cohort studies showed different results generally; cohort studies revealed no significant effect on the risk of colon cancer among the patients taking statins [37]. Similar results were obtained in seven case-control studies [4]. However, two large observational studies reported a reduction in the risk of colon and rectum cancer by $35-43 \%$ among patients taking statins in comparison to those not taking these drugs [38, 39]. It should be kept in mind, however, that colon cancer risk is, to a large extent, influenced by external factors (such as diet, physical activity, other medicines, screening) which may not have been taken into account in observational studies.

Lee et al. [40] reported that current statin use compared with non-users was not associated with colorectal cancer or colon cancer, but was associated with rectal cancer (Table 2).

Table 2. The latest research on the relationship between statin use and colorectal cancer

\begin{tabular}{|c|c|c|}
\hline Author, year & Number of cases & Results [point estimate $(95 \% \mathrm{Cl})]^{* *}$ \\
\hline Lee et al. $2011[40]$ & & $\begin{array}{l}\text { Association with colorectal cancer in statin users vs. non-users: } R R=0.99(0.86-1.14) \\
\text { Association with colon cancer in statin users vs. non-users : } R R=1.10(0.94-1.29) \\
\text { Association with rectal cancer in statin users vs. non-users } \\
R R=0.59(0.41-0.84)\end{array}$ \\
\hline Lakha et al. 2012 [42] & 603 & $\begin{array}{l}\text { Risk of colorectal cancer in statin users vs. non-users } \\
\text { OR 0.49; } 95 \% \mathrm{Cl}: 0.49-1.36 ; p=0.17 \\
\text { Colorectal cancer specific mortality in statin users vs. non-users } \\
\text { OR } 0.33 ; 95 \% \mathrm{Cl}: 0.08-1.35 ; p=0.12\end{array}$ \\
\hline Ng et al. 2011 [43] & 842 & $\begin{array}{l}\text { Cancer recurrence or death in statin users vs. non-users } \\
\mathrm{HR}=1.04,95 \% \mathrm{Cl}: 0.73-1.49 \\
\text { Recurrence-free survival and overall survival in cancer users vs. non-users } \\
\text { adjusted } \mathrm{HR} \text { of cancer recurrence }=1.14,95 \% \mathrm{Cl}: 0.77-1.69 \\
\text { adjusted } \mathrm{HR} \text { of death }=1.15,95 \% \mathrm{Cl}: 0.77-1.71\end{array}$ \\
\hline Mansouri et al. 2013 [41] & & Association with advanced colorectal neoplasia at colonoscopy: OR $=0.65(0.55-0.78)$ \\
\hline Mace et al. 2013 [44] & 407 & $\begin{array}{l}\text { Response to treatment in statin users vs. non-users } \\
65.7 \% \text { vs. } 48.7 \%, p=0.004\end{array}$ \\
\hline
\end{tabular}

** $O R$-odds ratio; $R R$ - relative risk; $H R$ - hazard ratio; $C l$ - confidence interval; relative to non-users of statin 
According to Mansouri et al. [41] statins users were less likely to have advanced neoplasia at colonoscopy (Table 2).

To investigate the association between statin use and colorectal cancer risk and survival, Lakha et al. [42] analyzed 603 cases (309 statin users and 294 non-users) from the Scottish Study of Colorectal Cancer (SOCCS). They found a statistically significant association between statin intake and colorectal cancer risk (OR 0.49; 95\% Cl: 0.491.36 ; $p=0.17$ ), but no significant association between statin intake and colorectal cancer specific mortality (OR 0.33; 95\% Cl: 0.08-1.35; $p=0.12$ ).

Recent clinical studies suggest that there are differences in response to statin use between colon and rectal cancer. For instance, we present studies which extract these two types of cancer.

$\mathrm{Ng} \mathrm{K}$ et al. [43] performed a prospective observational study of 842 patients with stage III colon cancer enrolled in a randomized adjuvant chemotherapy trial to investigate the relationship between statin use and survival. 134 (15.9\%) patients reported statin use after completing adjuvant chemotherapy. Disease-free survival (DFS) among statin users and nonusers was similar (hazard ratio [HR] of cancer recurrence or death $=1.04,95 \% \mathrm{Cl}$ : 0.73-1.49). Recurrence-free survival (RFS), and OS (overall survival) were also similar between statin users and nonusers (adjusted $\mathrm{HR}$ of cancer recurrence $=1.14,95 \% \mathrm{Cl}$ : 0.77-1.69; adjusted $\mathrm{HR}$ of death $=1.15,95 \% \mathrm{Cl}$ : 0.77-1.71). Statin use during and after adjuvant chemotherapy was not associated with improved DFS, RFS, or OS in patients with stage III colon cancer, regardless of KRAS mutation status.

By contrast, 407 patients with primary rectal adenocarcinoma who underwent neoadjuvant therapy, then proctectomy, were included in a retrospective cohort study based on data from a prospectively maintained colorectal cancer database. The 2 cohorts were defined by statin use during neoadjuvant chemoradiation. Ninety-nine patients (24.3\%) took a statin throughout the entire course of neoadjuvant therapy. Patients in the statin cohort were more likely to have a better response than those not taking a statin (65.7\% vs. $48.7 \%, p=0.004)$. According to these data, statin therapy is associated with an improved response of rectal cancer to neoadjuvant chemoradiation [44].

In vitro data also support a role for statins as adjuncts to chemotherapy in colorectal cancer. Simvastatin may overcome resistance to epidermal growth factor receptor inhibition with cetuximab in KRAS-mutated colon cancer cells and lovastatin has been shown to enhance chemosensitivity to 5 -fluorouracil [13].
The latest research has shown the existence of a genetic polymorphism in the gene of HMG-CoA reductase (HMGCR). This phenomenon concerns one nucleotide, and is associated with the occurrence of genotype A/A and $T / T$. In colon cancer cell lines, the reduction in cholesterol level after statin treatment was substantially stronger in cells carrying the A/A genotype [45].

\section{Statins and other most-frequent cancers}

A meta-analysis conducted by Tan et al. analyzed the results of 19 studies and showed no relationship between taking statins and the reduction in the risk of lung cancer. No correlation was observed among randomized controlled trials (RR 0.91; 95\% Cl: 0.76-1.09) cohort studies (RR 0.94; 95\% Cl: 0.82-1.07), or case-control studies (RR 0.82; 95\% Cl: 0.57-1.16) [46].

A study conducted by Leigh et al. [47] did not show a significant association between statin use and brain metastases from lung cancer (Table 3).

According to Stavrou et al. [48], discontinuation of statin therapy in cancer patients was associated with regionalized and distant disease spread (Table 3). The results of the meta-analysis by Tan et al. [49] suggest that there is no association between statin use and the risk of lung cancer (Table 3).

The impact of statins on the risk of developing breast cancer has not been clearly confirmed yet. Undela et al. conducted a large meta-analysis including 24 studies (including 13 cohort studies and 11 case-control) which researched more than 2.4 million participants (including 76,759 cases of breast cancer). The use of statins did not significantly affect the risk of breast cancer $(R R=0.99$, 95\% Cl: 0.94-1.04). The length of treatment with statins was taken into account in this study. Long-term treatment did not significantly affect the risk of developing breast cancer ( $R R=1.03,95 \% \mathrm{Cl}$ : 0.96) [50].

In turn, the case-control study conducted by McDougall et al. [51] showed that long-term use of statins was associated with increased risks of invasive lobular carcinoma and ductal carcinoma (Table 4).

Despite conflicting results, it appears that statins have a positive effect on the histological subtype of breast cancer by increasing the percentage of lower staging and grading [52].

Because of suggestions that statins have anti-inflammatory properties and anti-tumor effects, Brewer et al. [53] reviewed 723 patients diagnosed with primary inflammatory breast cancer to test the effect of statins on

Table 3. The latest research on the relationship between statin use and lung cancer

\begin{tabular}{|c|c|c|}
\hline Author, year & Number of cases & Results [point estimate $(95 \% \mathrm{Cl})]^{\star *}$ \\
\hline Leigh et al. 2011 [47] & 252 & $\begin{array}{l}\text { Association between statin use and brain metastases in lung cancer: } \\
\mathrm{HR}=1.20(0.68-2.13)\end{array}$ \\
\hline Stavrou et al. 2012 [48] & 1731 & $\begin{array}{l}\text { Association between discontinuation of statin therapy and lung cancer: } \\
\mathrm{HR}=1.99(1.32-3.00)\end{array}$ \\
\hline Tan et al. 2013 [46] & 38013 & $\begin{array}{l}\text { Association between statin use and lung cancer: } \\
\mathrm{RR}=0.94(0.82-1.07)\end{array}$ \\
\hline
\end{tabular}


Table 4. The latest research on the relationship between statin use and breast cancer

\begin{tabular}{|c|c|c|}
\hline Author, year & Number of cases & Results [point estimate $(95 \% \mathrm{Cl})]^{\star *}$ \\
\hline $\begin{array}{l}\text { McDougall et al. } 2013 \\
{[51]}\end{array}$ & 2886 & $\begin{array}{l}\text { Current use of statins } \geq 10 \text { years without hypercholesterolemia: } \\
-1.83 \times \text { increased risk of intraductal carcinoma }(\mathrm{Cl}: 1.14-2.93) \\
-1.97 \times \text { increased risk of lobular carcinoma }(\mathrm{Cl}: 1.25-3.12) \\
\text { Current use of statins } \geq 10 \text { years with hypercholesterolemia: } \\
->2 \times \text { increased risk of intraductal carcinoma }(\mathrm{OR}=2.04, \mathrm{Cl}: 1.17-3.57) \\
\text { and lobular carcinoma }(\mathrm{OR}=2.43, \mathrm{Cl}: 1.40-4.21)\end{array}$ \\
\hline Brewer et al. 2013 [53] & 723 & $\begin{array}{l}\text { Progression-free survival in statin users vs. non-users } \\
\mathrm{HR}=0.49 ; 95 \% \mathrm{Cl}: 0.28-0.84 ; p<0.01\end{array}$ \\
\hline Ahern et al. 2011 [55] & 18,769 & $\begin{array}{l}\text { Association between the risk of recurrence and simvastatin use: Adjusted 10-year risk } \\
\text { difference: } 20.10(\mathrm{Cl}: 20.11-20.08) \\
\text { Association between the risk of recurrence and hydrophilic statin use: Adjusted 10-year } \\
\text { risk difference: } 0.05(\mathrm{Cl}: 20.01-0.11)\end{array}$ \\
\hline Nickels et al. 2013 [54] & 3189 & $\begin{array}{l}\text { Association with increased overall mortality in statins users vs. non-users: } \\
\text { HR } 1.21 ; 95 \% \mathrm{Cl}: 0.87-1.69 \\
\text { No association with breast cancer-specific mortality: } \\
\text { HR } 1.04 ; \mathrm{Cl}: 0.67-1.60 \\
\text { Reduced risk of breast cancer recurrence in statin users vs. non-users: } \\
\text { HR } 0.83,95 \% \mathrm{Cl}: 0.54-1.24\end{array}$ \\
\hline
\end{tabular}

${ }^{* *} O R$ - odds ratio; $R R$ - relative risk; $H R$ - hazard ratio; $\mathrm{Cl}$ - confidence interval; relative to non-users of statin

this type of cancer. Statin users were defined as being on statins at the initial evaluation. The analysis showed that weakly lipophilic to hydrophilic (H-statin) were associated with significantly improved PFS (progression-free survival) compared with no statin $(\mathrm{HR}=0.49 ; 95 \% \mathrm{Cl}: 0.28-0.84$; $p<0.01)$. Results should be confirmed in a randomized study.

Nickels et al. [54] analyzed data coming from a German prospective cohort study (MARIE plus) concerning 3189 patients over 50 years of age, diagnosed with breast cancer. Self-reported use of lipid-lowering drugs (mostly statins) was non-significantly associated with increased overall mortality (HR 1.21 95\% Cl: 0.87-1.69) but no association with breast cancer-specific mortality was found (HR 1.04, $\mathrm{Cl}$ : 0.67-1.60). Statins were non-significantly associated with reduced risk of breast cancer recurrence (HR 0.83 , 95\% Cl: 0.54-1.24). These findings support the previous ones of an improved prognosis associated with statin use in the case of breast cancer.

Ahern et al. [55] found that simvastatin was associated with a reduced risk for breast cancer recurrence, whereas no association between hydrophilic statin use and breast cancer recurrence was observed (Table 4).

In conclusion, statins are a widely used group of drugs for heart disease; however, cardiovascular disease and cancer are the two main causes of death worldwide. Each year we learn more and more about the potential mechanisms of action of statins; nevertheless, the subject has not yet been exhausted and needs further investigation. A multitude of studies and results confirms, with growing certainty, the beneficial effect of statins on the risks of cancer and even a decrease in the mortality associated with cancer. So far the exposure to statins was linked both with cancer cases in general and certain types of cancer specifically.

Thanks to these positive reports the number of large, reliable studies that present the full value of statins for pri- mary and secondary prevention, as well as their potential value as part of cancer therapy, will increase. Undoubtedly, the relationship between the mechanism of action of statins and their impact on the development of cancer is complex and requires further observation.

The authors declare no conflict of interest.

\section{References}

1. Briel M, Vale N, Schwartz GG, de Lemos JA, et al. Updated evidence on early statin therapy for acute coronary syndromes: Meta-analysis of 18 randomized trials involving over 14,000 patients. Int J Cardiol 2012; 158: 93-100

2. Baigent C, Keech A, Kearney PM, et al. Cholesterol Treatment Trialists' (CTT) Collaborators. Efficacy and safety of cholesterol-lowering treatment: prospective meta-analysis of data from 90,056 participants in 14 randomised trials of statins. Lancet 2005; 366: 1267-78

3. Yeganeh B, Wiechec E, Ande SR, et al. Targeting the mevalonate cascade as a new therapeutic approach in heart disease, cancer and pulmonary disease. Pharmacol Ther 2014; 143: 87-110.

4. Boudreau DM, Yu O, Johnson J. Statin use and cancer risk: a comprehensive review. J.Expert Opin Drug Saf 2010; 9: 603-21.

5. Kamat AM, Nelkin GM. Atorvastatin: a potential chemopreventive agent in bladder cancer. Urology 2005; 66: 1209-12.

6. Wood WG, Igbavboa U, Muller WE, Eckert GP. Statins, Bcl-2, and apoptosis: cell death or cell protection? Mol Neurobiol 2013; 48: 308-14.

7. Chen J, Liu B, Yuan J, Yang J, Zhang J, An Y, Tie L, Pan Y, Li X. Atorvastatin reduces vascular endothelial growth factor (VEGF) expression in human non-small cell lung carcinomas (NSCLCS) via inhibition of reactive oxygen species (ROS) production. Mol Oncol 2012; 6: 62-72.

8. Pich C, Teiti I, Rochaix P, Mariamé B, Couderc B, Favre G, Tilkin-Mariamé AF. Statins reduce melanoma development and metastasis through MICA overexpression Front Immunol 2013; 4: 62.

9. Mannello F, Tonti GA. Statins and Breast Cancer: May Matrix Metalloproteinase be the Missing Link. Cancer Invest 2009; 27: 466-70.

10. Falcone D,2, Gallelli L, Di Virgilio A, Tucci L, Scaramuzzino M, Terracciano R, Pelaia G, Savino R. Effects of simvastatin and rosuvastatin 
on RAS protein, matrix metalloproteinases and NF-kB in lung can cer and in normal pulmonary tissues. Cell Prolif 2013; 46: 172-82.

11. López-Otín C, Matrisian LM. Emerging roles of proteases in tu mour suppression. Nat Rev Cancer 2007; 7: 800-8.

12. Pedersen TR. Pleiotropic effects of statins: evidence against benefits beyond LDL-cholesterol lowering. Am J Cardiovasc Drugs 2010; 10: 10-7.

13. Lochhead P, Chan T. Statins and Colorectal Cancer. Clin Gastroenterol Hepatol 2013; 11: 109-18.

14. Jialal I, Stein D, Balis D, Grundy SM, Adams-Huet B, Devaraj S. Effect of hydroxymethyl glutaryl coenzyme a reductase inhibitor therapy on high sensitive C-reactive protein levels. Circulation 2001; 103: 1933-5.

15. Park KW, Hwang KK, Cho HJ et al. Simvastatin enhances endothelial differentiation of peripheral blood mononuclear cells in hypercholesterolemic patients and induces pro-angiogenic cytokine IL-8 secretion from monocytes. Clin Chim Acta 2008; 388: 156-66.

16. Bruegel M, Teupser D, Haffner I, Mueller M, Thiery J. Statins reduce macrophage inflammatory protein-1alpha expression in hu man activated monocytes. Clin Exp Pharmacol Physiol 2006; 33: 1144-9.

17. Waldman A., Kritharides L. The pleiotropic effects of HMGCoA re ductase inhibitors: their role in osteoporosis and dementia. Drugs 2003; 63: 139-52

18. Xia Z, Tan MM, Wong WW, Dimitroulakos J, Minden MD, Penn LZ. Blocking protein geranylgeranylation is essential for lovastatin-induced apoptosis of human acute myeloid leukemia cells. Leukemia 2001; 15: 1398-407.

19. Mausner-Fainberg K, Luboshits G, Mor A, Maysel-Auslender S, Rubinstein A, Keren G, George J. The effect of HMG-CoA reductase in hibitors on naturally occurring CD4+CD25+T cells. Atherosclerosis 2008; 197: 829-39.

20. Curiel TJ. Tregs and rethinking cancer immunotherapy. J Clin Invest 2007; 117: 1167-74.

21. Platz EA, Clinton SK, Giovannucci E. Association between plasma cholesterol and prostate cancer in the PSA era. Int J Cancer 2008; 123: $1693-8$

22. Nielsen SF, Nordestgaard BG, Bojesen SE. Statin use and reduced cancer-related mortality. N Engl J Med 2012; 367: 1792-802.

23. Solomon KR, Freeman MR. Do the cholesterol-lowering properties of statin affect cancer risk? Trends Endocrinol Metab 2008; 19: 113-21.

24. Nelson PS, Clegg N, Arnold H, Ferguson C, Bonham M, White J, Hood L, Lin B. The program of androgen-responsive genes in neoplastic prostate epithelium. Proc Natl Acad Sci U S A 2002; 99 : 11890-5.

25. Bansal D, Undela K, D'Cruz S, Schifano F. Statin use and risk of prostate cancer: a meta-analysis of observational studies. PLoS One 2012; 7 (10): e46691.

26. Murtola TJ, Tammela TL, Lahtela J, Auvinen A. Cholesterol-lowering drugs and prostate cancer risk: a population-based case-control study. Cancer Epidemiol Biomarkers Prev 2007; 16: 2226-32.

27. Tan N, Klein EA, Li J, Moussa AS, Jones JS..Statin use and risk of prostate cancer in a population of men who underwent biopsy. J Urol 2011; 186: 86-90.

28. Yu O, Eberg M, Benayoun S, Aprikian A, Batist G, Suissa S, Azoulay L. Use of statins and the risk of death in patients with prostate cancer. J Clin Oncol 2014; 32: 5-11.

29. Soto DE, Daignault S, Sandler SM, Ray ME. No effect of statins on biochemical outcomes after radiotherapy for localized prostate cancer. Urology 2009; 73:158-62.

30. Allott EH, Howard LE, Cooperberg MR, Kane CJ, Aronson WJ, Terris MK, Amling CL, Freedland SJ. Postoperative statin use and risk of biochemical recurrence following radical prostatectomy: Results from the SEARCH database. BJU Int 2014; 3 (doi: 10.1111/ bju.12720).

31. Chao C, Jacobsen SJ, Xu L, Wallner LP, Porter KR, Williams SG.Use of statins and prostate cancer recurrence among patients treated with radical prostatectomy. BJU Int 2013; 111: 954-62.

32. Scosyrev E, Tobis S, Donsky H, Wu G, Joseph J, Rashid H, Messing E. Statin use and the risk of biochemical recurrence of prostate cancer after definitive local therapy: a meta-analysis of eight cohort studies. BJU Int 2013; 111 (3 Pt B): E71-7.
33. Singh PP, Singh S. Statins are associated with reduced risk of gas tric cancer: a systematic review and meta-analysis. Ann Oncol 2013; 24: 1721-30.

34. Singh S, Singh AG, Singh PP, Murad MH, lyer PG. Statins are associated with reduced risk of esophageal cancer, particularly in patients with Barrett's esophagus: a systematic review and meta-analysis. Clin Gastroenterol Hepatol 2013; 11: 620-9.

35. Singh S, Singh PP, Singh AG, Murad MH, Sanchez W. Statins are associated with a reduced risk of hepatocellular cancer: a systematic review and meta-analysis. Gastroenterol 2013; 144: 323-32.

36. van Duijnhoven FJ, Bueno-De-Mesquita HB, Calligaro M, Jenab M Pischon T, Jansen EH. Blood lipid and lipoprotein concentrations and colorectal cancer risk in the European Prospective Investigation into Cancer and Nutrition. Gut 2011; 60: 1094-102.

37. Bardou M, Barkun A, Martel M. Effect of statin therapy on colorectal cancer. Gut 2010; 59: 1572-85.

38. Poynter JN, Gruber SB, Higgins PD, Almog R, Bonner JD, Rennert HS, Low M, Greenson JK, Rennert G. Statins and the risk of colorectal cancer. N Engl J Med 2005; 352: 2184-92.

39. Farwell WR, Scranton RE, Lawler EV, Lew RA, Brophy MT, Fiore LD, Gaziano JM. The association between statins and cancer incidence in a veterans population. J Natl Cancer Inst 2008; 100: 134-9.

40. Lee JE, Baba Y, Ng K, Giovannucci E, Fuchs CS, Ogino S, Chan AT. Statin use and colorectal cancer risk according to molecular subtypes in two large prospective cohort studies. Cancer Prev Res (Phila) 2011; 4: 1808-15.

41. Mansouri D, McMillan DC, Roxburgh CS, Crighton EM, Horgan PG. The impact of aspirin, statins and ACE-inhibitors on the presentation of colorectal neoplasia in a colorectal cancer screening programme. Br J Cancer 2013; 109: 249-56.

42. Lakha F, Theodoratou E, Farrington SM, Tenesa A, Cetnarskyj R, Din FV, Porteous ME, Dunlop MG, Campbell H. Statin use and association with colorectal cancer survival and risk: case control study with prescription data linkage. BMC Cancer 2012; 22: 487.

43. Ng K, Ogino S, Meyerhardt JA, et al. Relationship between statin use and colon cancer recurrence and survival: results from CALGB 89803. J Natl Cancer Inst 2011; 103: 1540-51.

44. Mace AG, Gantt GA, Skacel M, Pai R, Hammel JP, Kalady MF. Statin therapy is associated with improved pathologic response to neoadjuvant chemoradiation in rectal cancer. Dis Colon Rectum 2013; 56: 1217-27.

45. Lipkin SM, Chao EC, Moreno V, Rozek LS, Rennert H, Pinchev M, Dizon D, Rennert G, Kopelovich L, Gruber SB. Genetic variation in 3-hydroxy-3-methylglutaryl CoA reductase modifies the chemopreventive activity of statins for colorectal cancer. Cancer Prev Res 2010; 3: 597-603.

46. Tan M, Song X, Zhang G, Peng A, Li X, Li M, Liu Y, Wang C. Statins and the risk of lung cancer: a meta-analysis. PLoS One 2013; 8: e57349.

47. Leigh D, Eken J, Beal JR, Ganti AK, Sahmoun AE. Statins use and risk for brain metastasis from lung cancer. Cancer Invest 2011; 29: 68-72.

48. Stavrou EP, Buckley N, Olivier J, Pearson SA. Discontinuation of statin therapy in older people: does a cancer diagnosis make a difference? An observational cohort study using data linkage. BMJ Open 2012; 2 (3) pii: e000880.

49. Tan M, Song X, Zhang G, Peng A, Li X, Li M, Liu Y, Wang C. Statins and the risk of lung cancer: a meta-analysis. PLoS One 2013; 8 (2): e57349.

50. Undela K, Srikanth V, Bansal D. Statin use and risk of breast cancer: a meta-analysis of observational studies. Breast Cancer Res Treat 2012; 135: 261-9

51. McDougall JA, Malone KE, Daling JR, Cushing-Haugen KL, Porter $\mathrm{PL}$, Li Cl. Long-term statin use and risk of ductal and lobular breast cancer among women 55-74 years of age. Cancer Epidemiol Biomarkers Prev 2013; 22: 1529-37

52. Wysocki PJ, Mackiewicz A. Controversies related to the use of agents with a potential anticancer activity. Wspolczesna Onkologia 2006; 10: 408-13. 
53. Brewer TM, Masuda H, Liu DD, et al. Statin use in primary inflammatory breast cancer: a cohort study. Br I Cancer 2013; 109: 318-24

54. Nickels S, Vrieling A, Seibold P, Heinz J, Obi N, Flesch-Janys D, Chang-Claude J. Mortality and recurrence risk in relation to the use of lipid-lowering drugs in a prospective breast cancer patient cohort. PLoS One 2013; 8 (9): e75088.

55. Ahern TP, Pedersen L, Tarp M, Cronin-Fenton DP, Garne JP, Silliman RA, Sørensen HT, Lash TL. Statin prescriptions and breast cancer recurrence risk: a Danish nationwide prospective cohort study. J Natl Cancer Inst 2011; 103: 1461-8.

\section{Address for correspondence}

\section{Aleksandra Stryjkowska-Góra}

Department of Clinical Oncology

Podkarpackie Oncological Center

Chopina 2

35-055 Rzeszow, Poland

e-mail: ostryj@o2.pl

Submitted: 22.11.2013

Accepted: 11.04.2014 